\title{
Determinants of Malignant Transformation in Fibrocystic Disease of Breast
}

\author{
Ketan Vagholkar \\ Department of Surgery, Dr. D. Y. Patil Medical College, Navi Mumbai, India \\ Email: kvagholkar@yahoo.com
}

Received 4 April 2014; revised 22 April 2014; accepted 28 April 2014

Copyright (@ 2014 by author and Scientific Research Publishing Inc.

This work is licensed under the Creative Commons Attribution International License (CC BY).

http://creativecommons.org/licenses/by/4.0/

\begin{abstract}
Background: Fibrocystic disease of the breast in one of the commonest diseases in women above 30 years of age. The assumption of it being innocuous and benign is questionable with increased incidence of malignancies developing in these women. Introduction: Understanding the pathophysiology of fibrocystic disease is essential for identifying determinants of malignant change. Case Report: A case of carcinoma of breast developing in a longstanding and recurrent fibrocystic disease is reported. Discussion: The pathological changes including the influence of hormones on the natural history of the disease are discussed to identify the determinants of malignant transformation. Conclusion: Breast cyst fluid, patterns of cellular lining of the cysts, multiplicity, recurrence and patterns of cellular morphology are important determinants of malignant change.
\end{abstract}

\section{Keywords}

Fibrocystic Disease Breast Carcinoma

\section{Introduction}

Fibrocystic disease of breast is one of the commonest diseases affecting women in age group of 30 - 50 yrs. Traditionally the disease has always been described as benign in nature with very low or almost no potential to develop into a malignant lesion. However, studies now reveal that not all cases of fibrocystic disease are absolutely benign but a select few can progress to malignant transformation [1]. The disease has been reported to be present and undergo malignant change even in males [2].

A case of a 52-year-old lady who underwent surgery for fibrocystic disease on two separate occasions on the same breast and later developed carcinoma in same breast is presented with a brief review of literature.

\section{Case Report}

52-year-old lady presented with history of an irregular mass in the right breast since 3 months. She gave history

How to cite this paper: Vagholkar, K. (2014) Determinants of Malignant Transformation in Fibrocystic Disease of Breast. Advances in Breast Cancer Research, 3, 54-58. http://dx.doi.org/10.4236/abcr.2014.32008 
of a lump in same breast 9 years back. Investigations then revealed the lump to be cystic in nature. Fluid was aspirated and did not reveal any malignant cells. Subsequently she was asymptomatic for quite some time.

In 2008, she developed 2 small lumps in the same breast which were excised. Histopathological examination of these lesions revealed fibrocystic disease. The cyst was fibrous with flattened epithelium, lining with foci of dilated ducts. One of these ducts showed intraductal epitheliosis. Nuclei were morphologically normal with some amount of perilobularinfiltration by lymphocytes. These details were mentioned on the report. Slides were unfortunately not available for detailed appraisal.

Patient was asymptomatic for a short period of time but again noticed lumps in the same breast. The lumps were excised surgically in 2012. Histological examination revealed fibrocystic disease of the breast with no further details.

3 months subsequent to this excision she again noticed similar lumps in right breast. These increased in size over a period of 1 year which she neglected until she was finally referred to my surgical facility.

On examination vital parameters were within normal limits. Physical examination did not reveal cervical lymphadenopathy, jaundice or bony tenderness. Abdominal examination did not reveal hepatomegaly or ascites.

Local examination of right breast revealed extensive scarring of whole breast, with an ulcerative lesion at superior aspect of right areola approximately $2.5 \mathrm{~cm}$ diameter with a deformed nipple (Figure 1).

Palpation revealed a large mass measuring $10 \mathrm{~cm}$ diameter involving entire right breast. The mass was adherent to the underlying pectoral muscles. Axillary lymph nodes were impalpable.

Multiple FNAC's revealed an intraductal carcinoma. Ultrasound examination of the abdomen did not reveal any metastases in the liver or any ascites.

In view of a locally advanced lesion two cycles of chemotherapy were administered preoperatively (CMF regimen) which led to regression of the lesion by approximately $25 \%$.

Subsequently she underwent right modified radical mastectomy with axillary clearance. At surgery the mass was found to be involving almost the entire pectoral is major muscle which was resected. (Figure 2) Axillary lymph nodes were not palpable. Axillary clearance was done (Figure 3) and the wound was closed with good approximation of flaps. Post-operative recovery was uneventful (Figure 4).

Histopathological evaluation of the specimen revealed the mass to be an infiltrating ductal carcinoma. Theresection margins were free of tumour. However lymphovascular invasion with involment of 5 axillary lymph nodes was detected. The hormonal receptor status was positive for oestrogen receptors. She is presently under go completion of chemotherapy followed by tamoxifen therapy.

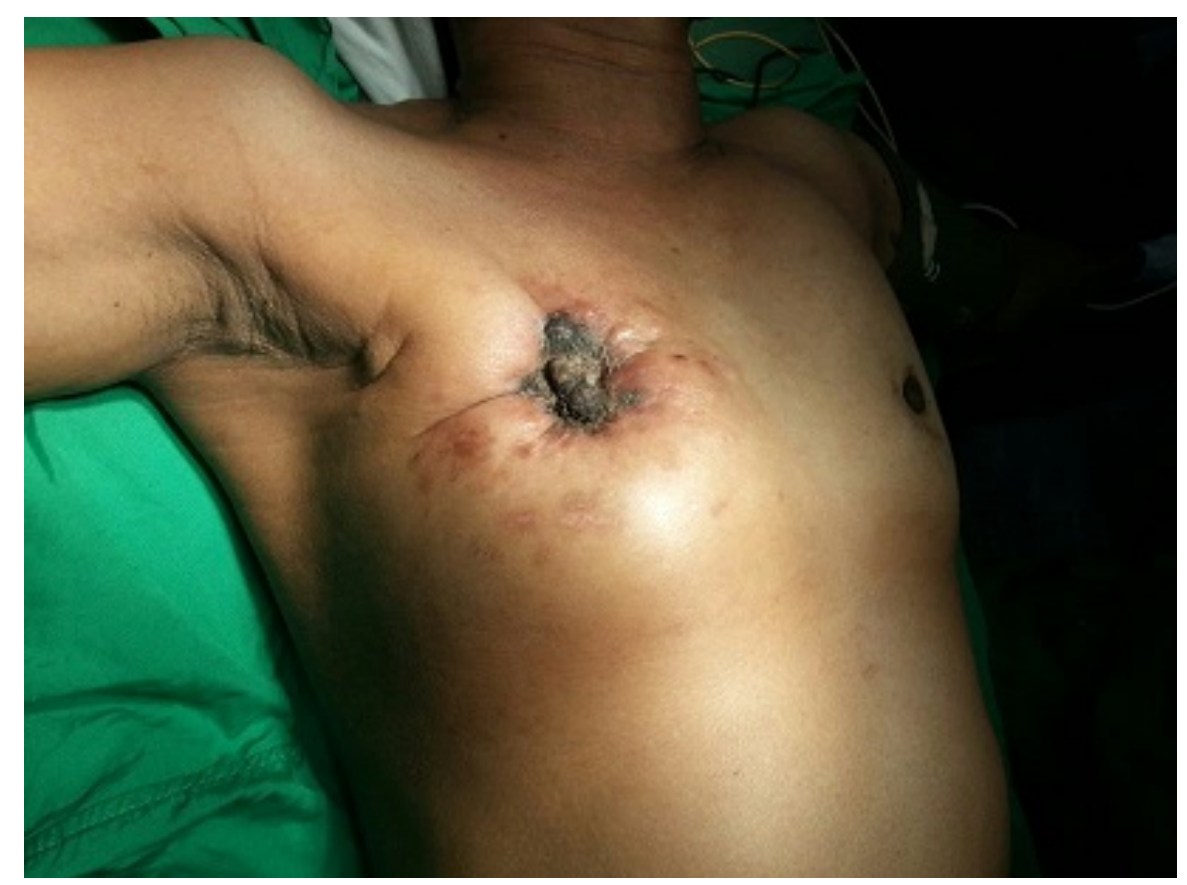

Figure 1. Pre-operative photograph showing a grossly scarred right breast. 


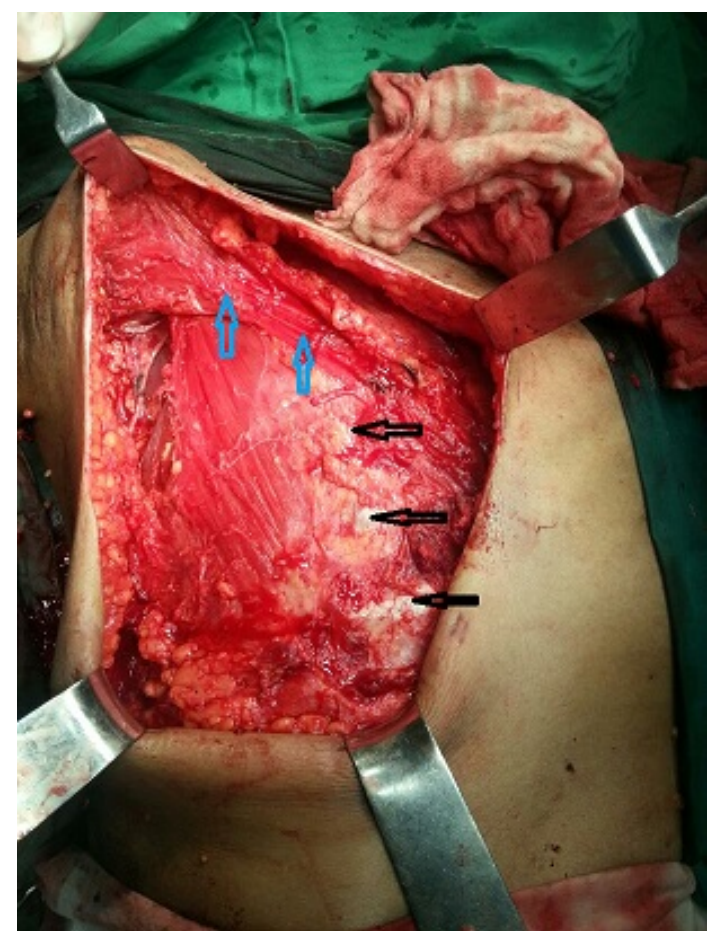

Figure 2. Intraoperative photograph showing exposure of the ribs after removal of amajor portion of the pectoralis major muscle. (exposed ribs marked by black arrows and the cut margin of the pectoralis major is marked by blue arrows).

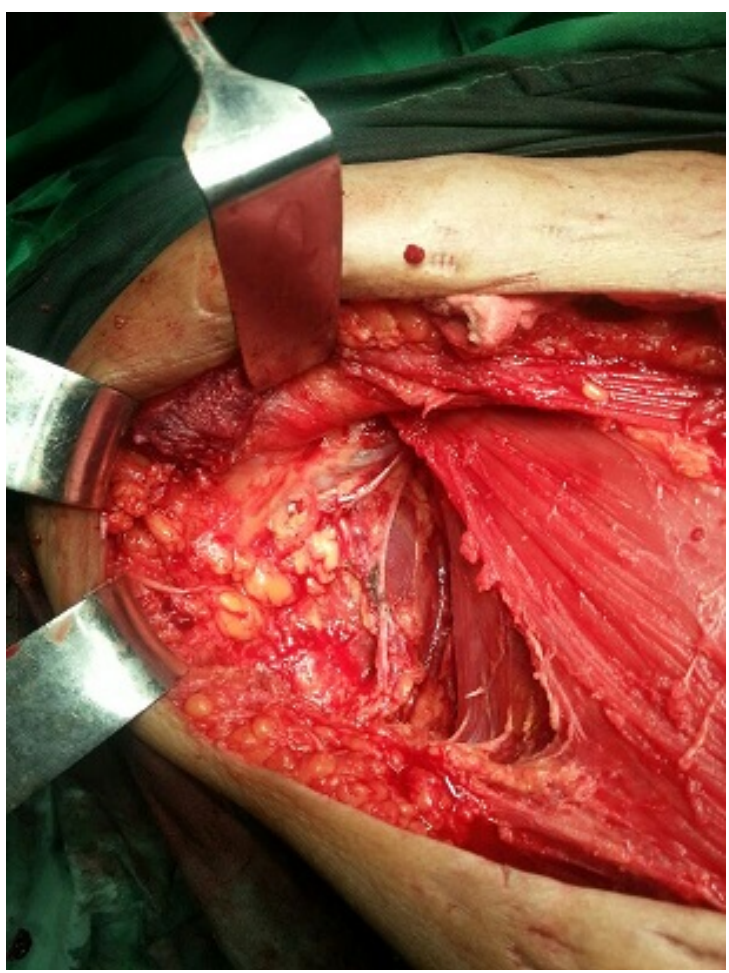

Figure 3. Intraoperative photograph showing the axilla after lymph node clearance. 


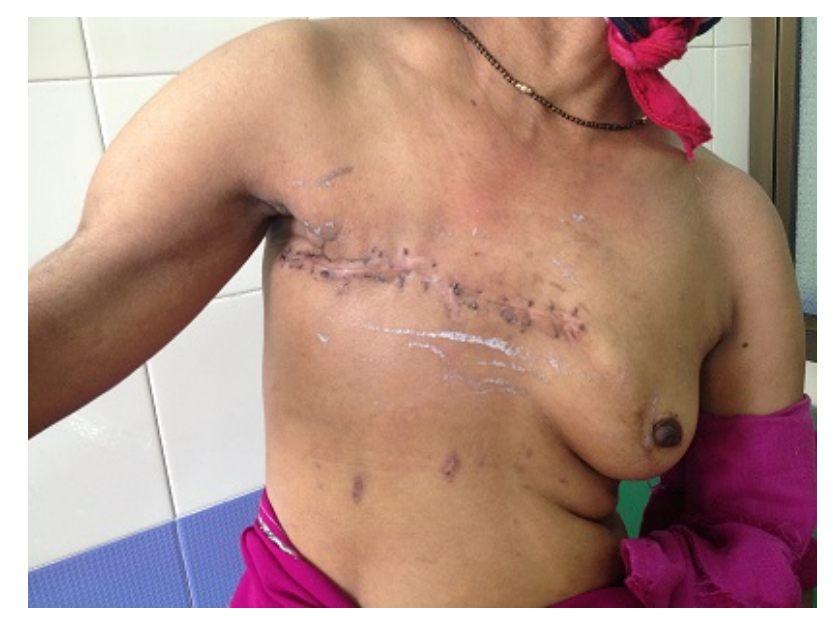

Figure 4. Postoperative state.

\section{Discussion}

The case presented highlights the fact that fibrocystic disease of breast in middle aged women should be taken seriously. Multiplicity of the cysts, the histology of the cysts removed previously and recurrence of the fibrocystic disease seems to have predisposed to malignant transformation. A detailed analysis of the nature of fibrocystic disease is what is required to determine the chances of malignant transformation. Fibrocystic disease is one of the components of ANDI (Aberrations of Normal Development and involution). Involutional changes in the breast are influenced by the genetic predisposition, socio-cultural factors and hormonal status. Many a times it is extremely difficult to evaluate all issues with an aim to identify those patients who will develop malignancy.

Fibrocystic disease of breast can be divided into non-proliferative and proliferative patterns.

Non proliferative patterns are associated with cystic changes and fibrosis [3]. The lesions are characterised by increase in fibrous stroma associated with dilatation of ducts leading to cysts which may either be single or multiple varying in size ranging from $1 \mathrm{~cm}$ to $5 \mathrm{~cm}$ [4] [5].

The nature of cyst fluid and lining of the cyst are important factors determining the chances of malignant transformation [3]. Based on nature of breast cyst fluid (BCF), cysts can be divided into two types:

Type I cyst: In this variety the potassium to sodium ratio $[\mathrm{K} / \mathrm{Na}]$ of the breast cyst fluid is more than 1.5. These women usually have either one pregnancy or are totally nulliparous. They are currently smokers and non coffee drinkers with evidence of apocrine changes. Women with type 1cysts are more prone to malignancy.

Type 2 cyst: These usually have decrease K/Na ratio and have less propensity to develop malignant changes.

Hormonal content or the steroid biochemistry of BCF has also been found to be different in the two types. Increased levels of androsterone-3- $\alpha, 17-\beta$-diol glucuronide, dihydroepiandrosterone sulphate (DHEA), oestrogen sulphate, androsterone glucuronide, testosterone and dihydrotestosterone are found in type 1 cysts as compared to type 2 cysts [6].

Type 2 breast cyst fluids have increased levels of progesterone and pregnenolone [6].

The influence of hormonal status of the patients with cystic diseases has also an impact on cyst fluid and breast cancer risk [7]. In women with type 1 cyst, oestrogen levels are high in luteal phase as compared to follicular phase. Whereas in type 2 cysts the DHEA level is higher in follicular phase as compared to luteal phase. Levels are lowest in both types of cysts in post-menopausal state [7].

Number and lining of cysts are also important factors. A Solitary cyst is usually lined by flattened epithelium and is less likely to develop malignant change whereas multiple cysts are usually apocrine in nature and prone to recurrence and malignant changes [4]. This was seen in the case presented.

Type 1 breast cyst fluid and multiplicity have higher chance of malignant changes.

Proliferative pattern of fibrocystic disease is yet another factor which can determine malignant transformation. Epithelial hyperplasia wherein there are more than 2 cell layers can evolve into a spectrum ranging from mild epithelial hyperplasia to atypical hyperplasia eventually leading to malignancy [8]. This was reported by the previous pathologist for the previously excised lumps in the case presented. The histological pattern of epithelial hyperplasia is variable. In a few cases the ducts or the ductules may be filled with orderly cuboidal cells within 
which small glandular patterns or fenestrations develop. Whereas in other cases proliferating epithelium may project as multiple small papillary excrescences into ductal lumen classically describes as ductal papillomatosis. These changes can be malignant precursors. In few cases, the hyperplastic cells have features resembling Carcinoma in situ. Such lesions can be described as atypical ductal hyperplasia. Both atypical ductal hyperplasia and lobular hyperplasia are associated with increased risk of invasive cancer.

Sclerosing adenosis is another type of fibrocystic disease which is less common than cyst and hyperplasia but whose features closely mimic cancer lesions containing marked intralobular fibrosis and proliferation of ductules and acini [8] [9].

Proliferation of luminal spaces (designated as adenosis) is usually lined by epithelial cells and myoepithelial cells thus yielding masses of small glands within a fibrous stroma. Marked stromal fibrosis may compress and distort proliferating epithelium and is always associated with adenosis. Hence designated as sclerosing adenosis [9].

\section{Conclusion}

Type 1 breast cyst fluid, multiplicity of cyst and recurrent disease, apocrine metaplasia, atypical ductal hyperplasia and sclerosing adenosis are important determinants for malignant transformation in a patient suffering from fibrocystic disease of breast.

\section{Acknowledgements}

We would like to thank the Dean of Dr. D. Y. Patil Medical College, Navi Mumbai, India for allowing us to publish this case report. We would also like to thank Mr. Parth K. Vagholkar for his help in typesetting the manuscripts.

\section{References}

[1] Habo, V., Habor, A., Copotiu, C. and Pantiru, A. (2010) Fibrocystic Breast Disease-Breast Cancer Sequence. Chirurgia (Bucur), 105, 191-194.

[2] Vagholkar, K., Dastoor, K. and Gopinathan, I. (2013) Intracystic Papillary Carcinoma in the Male Breast: A Rare Endpoint of a Wide Spectrum. Case Reports in Oncological Medicine, 2013, Article ID: 129353.

[3] Dixon, J.M., Lumsden, A.B. and Miller, W.R. (1985) The relationship of Cyst Type to Risk Factors for Breast Cancer and the Subsequent Development of Breast Cancer in Patients with Breast Cystic Disease. European Journal of Cancer and Clinical Oncology, 21, 1047-1050. http://dx.doi.org/10.1016/0277-5379(85)90289-5

[4] Naldoni, C., Costantini, M., Dogliotti, L., Bruzzi, P., Bucchi, L., Buzzi, G., Torta, M. and Angeli, A. (1992) Association of Cyst Type with Risk Factors for Breast Cancer and Relapse Rate in Women with Gross Cystic Disease of the Breast. Cancer Research, 52, 1791-1795.

[5] Dixon, J.M., Scott, W.N. and Miller, W.R. (1985) Natural History of Cystic Disease: The Importance of Cyst Type. British Journal of Surgery, 72, 190-192. http://dx.doi.org/10.1002/bjs.1800720311

[6] Angeli, A., Dogliott, L., Naldoni, C., Orlandi, F., Puligheddu, B., Caraci, P., Bucchi, L., Torta, M. and Bruzzi, P. (1994) Steroid Biochemistry and Categorization of Breast Cyst Fluid: Relation to Breast Cancer Risk. The Journal of Steroid Biochemistry and Molecular Biology, 49, 333-339. http://dx.doi.org/10.1016/0960-0760(94)90276-3

[7] Budai, B., Szamel, I., Sulyok, Z., Nemeth, M., Bak, M., Kralovanszky, J., Otto, S., Besznyak, I., Purohit, A., Parish, D.C. and Reed, M.J. (2000) Influence of Hormonal Status of Patients with Cystic Disease on the Composition of Cyst Fluid and Breast Cancer Risk. Anticancer Research, 5C, 3879-3886.

[8] Celis, J.E., Moreira, J.M., Gromova, I., Cabezon, T., Gromov, P., Shen, T., Timmermans, V. and Rank, F. (2007) Characterization of Breast Precancerous Lesions and Myoepithelial Hyperplasia in Sclerosing Adenosis with Apocrine Metaplasia. Molecular Oncology, 1, 97-119. http://dx.doi.org/10.1016/j.molonc.2007.02.005

[9] Wells, C.A. and El-Ayat, G.A. (2007) Non Operative Breast Pathology: Apocrine Lesions. Journal of Clinical Pathology, 60, 1313-1320. http://dx.doi.org/10.1136/jcp.2006.040626 